\title{
How are automatic processes elicited by intended actions?
}

\author{
Dana Ganor-Stern ${ }^{1 *}$, Joseph Tzelgov ${ }^{2}$ and Nachshon Meiran ${ }^{2}$ \\ ${ }^{1}$ Department of Psychology, Achva Academic College, MP. Shikmim, Israel \\ ${ }^{2}$ Department of Psychology, Ben-Gurion University of the Negev, Beer-Sheva, Israel \\ *Correspondence: danaga@bgu.ac.il \\ Edited by: \\ Asher Cohen, Hebrew University of Jerusalem, Israel
}

Keywords: automaticity, interference paradigm, task-dependence, automatic and intended actions

Although unintentionality is one of the key elements common to most traditional definitions of automaticity (e.g., Posner and Snyder, 1975; Shiffrin and Schneider, 1977; Hasher and Zacks, 1979; Jacoby et al., 1993; Tzelgov, 1997; Moors and De Houwer, 2006), more recent approaches pointed out that many automatic processes are affected and even elicited by intended processes (e.g., Bargh, 1994; Hommel, 2000; Tzelgov and Ganor-Stern, 2005; Yamaguchi and Proctor, 2012). However, there was no attempt to provide a systematic analysis of the different ways in which intended processes activate automatic ones. The present paper aims to fill this gap.

We view automatic processes as a product of interplay between information in long-term memory, reflecting life-long experience, and information in working memory, reflecting the requirement of the current situation. Such requirements are translated into task sets (Monsell et al., 2001), which activate the intended processes directly but may also activate some unintended processes indirectly. This activation of an unintended process (AUP) is a product of the overlap existing between the parameters of the intended process and those of unintended processes that are often highly practiced (Kornblum et al., 1990; Hommel, 2000).

Automatic processes can be triggered by AUP, and in some cases they will not start without it. Automatic processes differ in their dependence on AUP. Some automatic processes need very little AUP to occur, while for others, stronger AUP is needed (e.g., Bargh, 1989, 1992). Furthermore, AUP may not only trigger the occurrence of a process, but may also enhance its behavioral manifestation. For example, when the interference paradigm is used, the behavioral manifestation of the automatic processing, which is the interference effect, will be larger in conditions of strong vs. weak AUP.

We expand on the original taxonomy of dimensional overlap developed by Kornblum et al. (1990) and propose a classification of five levels of AUP, by which automatic processes are activated by intended ones. Furthermore, we demonstrate their effects using empirical findings of well-known indicators of automaticity. Note that a single task can provide AUP at multiple levels.

\section{AUP AT THE STIMULUS-LOCATION LEVEL}

The experimental task directs participants' attention to an area in space or to an object (e.g., Bundesen, 1990; Scholl, 2001). Strong AUP at the stimulus-location level occurs when the task directs the participant's attention to the place where the automatically processed information is located. Consequentially, it encourages the processing of all dimensions of this object (e.g., Kahneman and Treisman, 1984; Kramer and Jacobson, 1991; Pratt and Hommel, 2003).

Findings with the Stroop task demonstrate AUP at this level. In this task, naming the color of the ink in which a color word is printed is hampered when the color word and the ink color are incongruent vs. congruent, indicating the automaticity of word reading (Stroop, 1935). Separating the word from the task-relevant colored stimulus presumably reduces the AUP, and thus results in a reduced Stroop effect relative to a situation where they are presented as an integrated object (e.g., Kahneman and Henik, 1981; MacLeod, 1998; Lamers and Roelofs, 2007). Additionally, spreading visual attention too widely by presenting another word in the display reduces the Stroop effect, an effect referred to as the dilution effect (Kahneman and Chajczyk, 1983). On the other hand, narrowing visual attention to the letter level by coloring only a single letter in a color word causes a reduction in the Stroop effect (Besner et al., 1997).

\section{AUP AT THE STIMULUS-IDENTITY LEVEL}

The experimental task directs the participant's attention to a specific stimulus, which may be associated with one or more processes. Strong AUP at the stimulusidentity level exists when the task directs the participant's attention to a stimulus that is strongly associated with a particular highly practiced (yet, currently irrelevant) process. In such cases, attending to that stimulus might activate this process.

There is an especially strong association between words and the highly practiced skill of reading (Besner et al., 1997). As a consequence, attending to a word might activate the reading process and this should impair performance when the required task is not reading. Moreover, the activation of the reading process should increase with the resemblance of the stimulus to a word. Indeed, Monsell et al. (2001) showed that the slowing in a color naming task was dependent on the extent to which the non-words resembled words. Color naming was slower when the carrier stimulus resembled a word than when it did not. The difference between AUP at the stimulus location and at the stimulus identity level is similar to that between "where" and "what" in visual attention.

\section{AUP AT THE PROCESS LEVEL}

The experimental task indicates the nature of the process required. There are two types of AUP at the process level. First, the intention to perform a process might activate related processes. Second, the process 
required by a task might still be active even when it is no longer needed.

\section{AUP FROM THE PROCESS REQUIRED BY THE CURRENT TASK}

Experimental tasks require a wide variety of processes, such as naming, detection, classification, and comparison. The stronger the similarity or the association between the intended process and unintended ones is, the stronger the AUP. In this case, the process required by the task might activate related processes, perhaps through spreading activation.

Evidence for this type of AUP is provided, for example, by La Heij et al. (1998). Using the picture-word interference task, they found the gender congruency effect (difference in performance between trials in which the gender of the verbal title of the depicted object was congruent vs. incongruent with the gender of the word) only when participants produced noun phrases and not when they produced nouns only. Presumably the former activates gender-marking information to a greater extent than the latter does. Similar results were found in studies that looked at the effect of the grammatical category of the distractor word on performance in the same task (Pechmann and Zerbst, 2002; Pechmann et al., 2004). Analogous findings were reported by Vigliocco et al. (2005). Together, these studies suggest that the automatic activation of grammatical characteristics of an irrelevant stimulus during speech production depends on pre-activation of the specific grammatical information from the required task.

\section{AUP FROM THE PROCESS REQUIRED BY THE PREVIOUS TASK}

This type of AUP is strong when the unintended automatic process was required by the previous task. The processes required in a previous task, although not relevant anymore, might still be activated and influence the performance in the current task. The consistent pattern of poorer performance on task-switch trials (i.e., trials following a shift from one task to another) compared to task repetition trials is an example for such an effect (e.g., Kiesel et al., 2010; Meiran, 2010; Vandierendonck et al., 2010). It is partly due to carryover of activation from the previous task (e.g., Allport et al., 1994; Yeung et al., 2006).

\section{AUP AT THE STIMULUS-DIMENSION LEVEL}

The experimental task often requires a classification according to a certain dimension—size, color, polarity, etc. This might encourage the application of the same classification also to irrelevant stimuli. Strong AUP occurs when the dimension of interest is also applicable to other aspects or objects that are task-irrelevant (Kornblum et al., 1990; Kornblum and Lee, 1995).

Empirical evidence for this kind of AUP comes, for example, from the size congruency effect, which is found when a classification of digits according to physical size is required. Performance is enhanced when the numerical and physical sizes correspond, compared to when they do not, indicating the automatic processing of numerical magnitude (e.g., Henik and Tzelgov, 1982). In this case, the processing of the physical size required by the task might trigger the automatic processing of the irrelevant numerical size. Indeed, studies that used a luminance judgment found either no evidence for automatic numerical processing (Pinel et al., 2004) or a reduced effect (Rubinsten and Henik, 2005; Cohen Kadosh and Henik, 2006).

In a similar manner, the Stroop effect varies as a function of the overlap at the stimulus-dimension level between the relevant ink-color and irrelevant word. It is largest for color words, decreases for colorassociated words, and decreases even more for words unrelated to color (Klein, 1964; MacLeod, 1991; Sharma and McKenna, 1998; Risko et al., 2006).

The effect of AUP at the stimulusdimension level is also found for involuntary attention shifts. Folk et al. (1992) showed that the occurrence of involuntary shifts of attention depended on task demands and specifically, on the relation between the properties of the cue and the properties required to locate the target. They were present when the cue shared a feature property that was critical to the performance of the target task; for example, when the target was defined by color, colored cues produced involuntary attention shifts. Note that this AUP level differs from the previous one because AUP at the stimulus dimension refers to the stimulus dimension that is task-relevant, while AUP at the process level refers to the mental operation that is employed. Different processes might be applied to the same dimensions.

\section{AUP AT THE RESPONSE LEVEL}

The task set specifies the response categories and the way they are mapped onto the actual responses. Strong AUP occurs when the processing of the irrelevant dimension can be mapped onto the same set of responses specified for the relevant dimension. Such overlap may enhance the indications for automaticity. Indeed, larger Stroop effects are found for words that are part of the set of possible responses than for words that are not (Klein, 1964; MacLeod, 1991; Sharma and McKenna, 1998).

The present work could be viewed as an extension of Kornblum's dimensional overlap theory (Kornblum et al., 1990; Kornblum and Lee, 1995), which focused on stimulus-stimulus and stimulusresponse overlap. We added to this framework the AUP at the stimulus location, stimulus identity, and process levels. Moreover, we related the systematic analysis of levels of AUP to degrees of automaticity. Automatic processes differ in the extent to which they depend on activation from the intended task, consistent with a gradual approach to automaticity (e.g., Moors and De Houwer, 2006). Some automatic processes need very little AUP to occur, with the least amount of AUP provided at the levels of stimulus location and stimulus identity. In fact, AUP at the stimulus level might be present even when there is no task at hand. In such cases, automatic processing will occur whenever the relevant stimulus is attended. In other cases, additional preconditions need to be met (e.g., Bargh, 1989, 1992). Such preconditions are provided by the other levels of AUP. The automatic process might occur only when the intended task involves a related process, a similar stimulus-dimension or the same response set.

\section{SUMMARY}

Although past works on automaticity acknowledged the fact that automatic processes are affected and even elicited by intended ones, there was no attempt to analyze this influence in detail. The present paper proposed a systematic analysis of 
the ways the intended process activates or elicits the occurrence of the automatic one. Examples for the effects of the AUP levels on automatic processes in different domains demonstrate the generality of this analysis. Results from other paradigms such as the flanker and Simon tasks could nicely fit into this analysis, however they were omitted from this paper, due to space limitations. Note that the different AUP levels are not mutually exclusive and a certain task might produce multiple levels of AUP to the automatic process. This is the case of the color-word Stroop effect, where all levels of AUP operate, and this may account for the robustness of the effect.

AUP affects not only the presence of the automatic process but also its behavioral indicators. As described in this paper, numerous studies from different domains showed that stronger AUP produced larger and stronger behavioral indicators of automaticity compared to weak AUP.

\section{ACKNOWLEDGMENTS}

This research was supported by grants from the Israel Foundation Trustees and Israel Science Foundation (grant no. 906/12) to the first author.

\section{REFERENCES}

Allport, A., Styles, E. A., and Hsieh, S. (1994). "Shifting intentional set: exploring the dynamic control of tasks," in Attention and Performance XV: Conscious and Unconscious Processing, eds C. Umiltà and M. Moscovitch (Cambridge, MA: MIT Press), 421-452.

Bargh, J. (1989). "Conditional automaticity: varieties of automatic influence in social perception and cognition," in Unintended Thought, eds J. S. Uleman and J. Bargh (New York, NY: Guilford Press), 3-51.

Bargh, J. (1992). The ecology of automaticity: towards establishing the conditions needed to produce automatic processing effect. Am. J. Psychol. 105, 181-199. doi: $10.2307 / 1423027$

Bargh, J. (1994). "The four horsemen of automaticity: awareness, intention, efficiency, and control in social cognition," in Handbook of Social Cognition, eds R. S. J. Wyer and T. K. Srull (Hillsdale, NJ: Lawrence Erlbaum Associates, Inc.), 1-40.

Besner, D., Stolz, J., and Boutilier, C. (1997). The Stroop effect and the myth of automaticity. Psychon. Bull. Rev. 4, 221-225. doi: 10.3758/BF03209396

Bundesen, C. (1990). A theory of visual attention. Psychol. Rev. 97, 523-547. doi: 10.1037/0033295X.97.4.523
Cohen Kadosh, R., and Henik, A. (2006). A common representation for semantic and physical properties: a cognitive-anatomical approach. Exp. Psychol. 53, 87-94. doi: 10.1027/1618-3169.53.2.87

Risko, E., Schmidt, J., and Besner, D. (2006). Filling a gap in the semantic gradient: color associates and response set effects in the stroop task. Psych. Bull. Rev. 13, 310-315. doi: 10.3758/BF03193849

Folk, C. L., Remington, R., and Johnston, J. C. (1992). Involuntary covert orienting is contingent on attentional control settings. J. Exp. Psychol. Hum. Percept. Perform. 18, 1030-1044. doi: 10.1037/0096-1523.18.4.1030

Hasher, L., and Zacks, R. T. (1979). Automatic and effortful processes in memory. J. Exp. Psychol. Gen. 108, 356-388. doi: 10.1037/0096-3445.108.3.356

Henik, A., and Tzelgov, J. (1982). Is three greater than five: the relation between physical and semantic size in comparison tasks. Mem. Cogn. 10, 389-395. doi: 10.3758/BF03202431

Hommel, B. (2000). "The prepared reflex: automaticity and control is stimulus-response translation," in Control of Cognitive Processes: Attention and Performance XVIII, eds S. Monsell and J. Driver (Cambridge, MA: MIT Press), 247-273.

Jacoby, L., Ste-Marie, D., and Toth, J. P. (1993). "Redefining automaticity: unconscious influences, awareness, and control," in Attention, Selection, Awareness and Control: A Tribute to Donald Broadbent, eds A. Baddeley, D. and Weiskrantz (Oxford, UK: Oxford University Press), 261-282.

Kahneman, D., and Chajczyk, D. (1983). Test of automaticity of reading: dilution of the stroop effect by color-irrelevant stimuli. J. Exp. Psychol. Hum. Percept. Perform. 9, 497-509. doi: 10.1037/00961523.9.4.497

Kahneman, D., and Henik, A. (1981). "Perceptual organization and attention," in Perceptual Organization, eds M. Kubovy and J. R. Pomerantz (Hillsdale, NJ: Lawrence Erlbaum Associates), 181-211.

Kahneman, D., and Treisman, A. (1984). "Changing views of attention and automaticity," in Varieties of Attention, eds R. Parasuraman and D. R. Davies (Orlando, FL: Academic Press), 29-62.

Kiesel, A., Steinhauser, M., Wendt, M., Falkensteind, M., Jost, K., Philipp, A., et al. (2010). Control and interference in task switching-a review. Psychol. Bull. 136, 849-874. doi: 10.1037/a0019842

Klein, G. S. (1964). Semantic power measured through the interference of words with colornaming. Am. J. Psychol. 77, 576-588. doi: 10.2307/1420768

Kornblum, S., Hasbroucq, T., and Osman, A. (1990). Dimensional overlap: cognitive basis for stimulusresponse compatibility - a model and taxonomy. Psychol. Rev. 97, 253-270. doi: 10.1037/0033295X.97.2.253

Kornblum, S., and Lee, J.-W. (1995). Stimulusresponse compatibility with relevant and irrelevant stimulus dimensions that do and do not overlap with the response. J. Exp. Psychol. Hum. Percept. Perform. 21, 855-875. doi: 10.1037/00961523.21.4.855

Kramer, A., and Jacobson, A. (1991). Perceptual organization and focused attention: the role of objects and proximity in visual processing. Percept. Psychophys. 50, 267-284. doi: 10.3758/BF03206750
La Heij, W., Mak, P., Sander, J., and Willeboordse, E. (1998). The gender-congruency effect in pictureword tasks. Psychol. Res. 61, 209-219. doi: 10.1007/s004260050026

Lamers, M., and Roelofs, A. (2007). Role of Gestalt grouping in selective attention: Evidence from the Stroop task. Percept. Psychophys. 69, 1305-1314. doi: 10.3758/BF03192947

MacLeod, C. M. (1991). Half a century of research on the Stroop effect: an integrative review. Psychol. Bull. 109, 163-203. doi: 10.1037/00332909.109.2.163

MacLeod, C. M. (1998). Training on integrated versus separated stroop tasks: the progression of interference and facilitation. Mem. Cogn. 26, 201-211. doi: 10.3758/BF03201133

Meiran, N. (2010). "Task switching: mechanisms underlying rigid vs. flexible self-control," in Self Control in Society, Mind and Brain, eds R. Hassin, K. Ochsner and Y. Trope (New York, NY: Oxford University Press), 202-220. doi: 10.1093/acprof:oso/9780195391381.003.0011

Monsell, S., Taylor, T. J., and Murphy, K. (2001). Naming the color of a word: is it responses or task sets that compete. Mem. Cogn. 29, 137-151. doi: 10.3758/BF03195748

Moors, A., and De Houwer, J. (2006). Automaticity: a conceptual and theoretical analysis. Psychol. Bull. 132, 297-326. doi: 10.1037/0033-2909.132.2.297

Pechmann, T., and Zerbst, D. (2002). The activation of word class information during speech production. J. Exp. Psych. Learn. 28, 233-243. doi: 10.1037/0278-7393.28.1.233

Pechmann, T., Garrett, M., and Zerbst, D. (2004). The time course of recovery for grammatical category information during lexical processing for syntactic construction. J. Exp. Psychol. Learn. 30, 723-728. doi: 10.1037/0278-7393.30.3.723

Pinel, P., Piazza, M., Le Bihan, D., and Dehaene, S. (2004). Distributed and overlapping cerebral representations of number, size, and luminance during comparative judgments. Neuron 41, 1-20. doi: 10.1016/S0896-6273(04)00107-2

Posner, M. I., and Snyder, C. R. R. (1975). "Attention and cognitive control," in Information Processing and Cognition: The Loyola Symposium, ed R. L. Solso (Hillsdale, NJ: Erlbaum), 55-85.

Pratt, J., and Hommel, B. (2003). Symbolic control of visual attention: the role of working memory and attentional control settings. J. Exp. Psychol. Hum. Percept. Perform. 29, 835-845. doi: 10.1037/00961523.29.5.835

Rubinsten, O., and Henik, A. (2005). Automatic activation of internal magnitudes: a study of developmental dyscalculia. Neuropsychology 19, 641-648. doi: 10.1037/0894-4105.19.5.641

Scholl, B. J. (2001). Objects and attention: the state of the art. Cognition 80, 1-46. doi: 10.1016/S00100277(00)00152-9

Sharma, D., and McKenna, F. (1998). Differential components of the manual and vocal Stroop tasks. Mem. Cogn. 26, 1033-1040. doi: 10.3758/BF03201181

Shiffrin, R. M., and Schneider, W. (1977). Controlled and automatic human information processing. II. perceptual learning, automatic attending, and a general theory. Psychol. Rev. 84, 127-190. doi: 10.1037/0033-295X.84.2.127 
Stroop, J. R. (1935). Studies of interference in serial verbal reactions. J. Exp. Psychol. 18, 643-662. doi: 10.1037/h0054651

Tzelgov, J. (1997). Specifying the relations between automaticity and consciousness: a theoretical note. Conscious. Cogn. 6, 441-451. doi: 10.1006/ccog.1997.0303

Tzelgov, J., and Ganor-Stern, D. (2005). "Automaticity in processing ordinal information," in Handbook of Mathematical Cognition, ed J. I. D. Campbell (New York, NY: Psychology Press), 55-67.

Vandierendonck, A., Liefooghe, B., and Verbruggen, F. (2010). Task switching: interplay of reconfiguration and interference control. Psychol. Bull. 136, 601-626. doi: 10.1037/a0019791
Vigliocco, G., Vinson, D. P., and Siri, S. (2005). Semantic similarity and grammatical class in naming actions. Cognition 94, B91-B100. doi: 10.1016/j.cognition.2004.06.004

Yamaguchi, M., and Proctor, R. W. (2012). Multidimensional vector model of stimulusresponse compatibility. Psychol. Rev. 119, 272-303. doi: 10.1037/a0026620

Yeung, N., Nystrom, L. E., Aronson, J. A., and Cohen, J. D. (2006). Between-task competition and cognitive control in task switching. J. Neurosci. 26, 1429-1438. doi: 10.1523/JNEUROSCI.310905.2006

Received: 18 July 2013; accepted: 25 October 2013; published online: 13 November 2013.
Citation: Ganor-Stern D, Tzelgov J and Meiran N (2013) How are automatic processes elicited by intended actions? Front. Psychol. 4:851. doi: 10.3389/fpsyg. 2013.00851

This article was submitted to Cognition, a section of the journal Frontiers in Psychology.

Copyright (c) 2013 Ganor-Stern, Tzelgov and Meiran. This is an open-access article distributed under the terms of the Creative Commons Attribution License (CC BY). The use, distribution or reproduction in other forums is permitted, provided the original author(s) or licensor are credited and that the original publication in this journal is cited, in accordance with accepted academic practice. No use, distribution or reproduction is permitted which does not comply with these terms. 